\title{
Bed Sediment Influence on River Flow
}

\author{
Zygmunt Meyer $^{1}$ \\ ${ }^{1}$ Faculty of Civil Engineering, West Pomeranian University of Technology in Szczecin, Szczecin, Poland \\ Correspondence: Zygmunt Meyer, Faculty of Civil Engineering, West Pomeranian University of Technology in \\ Szczecin, Piastow Str.50 70-310 Szczecin, Poland. Tel: 48-914-494-371. E-mail: meyer@zut.edu.pl
}

\author{
Received: April 14, 2014 Accepted: May 12, 2014 Online Published: July 1, 2014 \\ doi:10.5539/enrr.v4n3p144 URL: http://dx.doi.org/10.5539/enrr.v4n3p144
}

\begin{abstract}
The paper presents the analysis of influence of bed sediment transport on river flow. The analysis is based upon earlier research of the author where the mechanism of flow in ice covered river and bottom sediment resistance was developed. In the present paper there is given mathematical description of the river banks influence on the basic hydraulic factors.
\end{abstract}

\section{Introduction}

In the years 1976-1977 the author was carrying research at the Imperial College of Science and Technology University of London, receiving scholarship of the British Council. The Head of the section of Hydraulics at that time was prof. J.R.D. Francis. One day prof. Francis performed an experiment concerning sediment transport and the river flow. He used flume: $25 \mathrm{~m}$ long, $1.0 \mathrm{~m}$ high and 0.4 width and he prepared steady flow in the flume. The depth was around $0.7 \mathrm{~m}$ and the bed was a rough but not movable. To the flowing stream of water, Professor added a volume of fine sand. When the volume of added sand reached certain amount, a bed sediment transport was created and suddenly the water level in the flume dropped down. There was a significant decreasement of the depth. It seemed that the bed sediment diminished the bed roughness. Or, the bed sediment lubricates the bottom of the flowing stream. That was the beginning of the presented here research.

The analysis of the flowing stream indicates that in the case at non movable bottom the stream tends to hydrodynamics equilibrium state based on energy losses. This principle creates the relation flow-depth. This principle can also be expressed in the term of other flow factor e.q. eddy viscosity coefficient at the bottom. The problem was investigated by the author in the previous paper Meyer $(2009 \mathrm{c})$. From that analysis, relationships come describing: eddy viscosity coefficient of water at the bottom, von Karman constant, the linear measure of bed roughness and Maning roughness coefficient. All those parameters appear in the modified logarithmic tachoida proposed by the author, Meyer (2009c, 2009d), and they can be used for calculations of river depth depending on river flow. On the other hand there exists a great number of methods for calculation of sediment stream van Rijn (1982); Zanke (2003); Graf (1984);Olsen at all (1995). Review of those methods applied to the sediment transport in Odra river was done by Meyer and Pluta (2001). From this research it comes that the Maning roughness coefficient calculated from bed sediment composition and flow, seems to be smaller that the one relevant for the case of non movable bed (by 0.004) and so the depth is smaller as well. It can be explained in the following way.

The hydrodynamic equilibrium state in the case of non movable bed requires eddy viscosity coefficient of water at the bottom Meyer $(2009 \mathrm{c}, 2009 \mathrm{~d})$. In the case of movable bed when bed sediment stream occurs the mixture of water and solid particles is created. The eddy viscosity coefficient of the mixture is much higher that the one for pure water i.e. kinematic viscosity of water. So now the equilibrium eddy viscosity coefficient of water at the bottom is fulfilled by roughness at the bottom and the existing there mixture of sediment.

The equilibrium can be now be achieved with smaller Maning roughness coefficient. And that means smaller depth. In the further part, the mechanism creating the equilibrium state is given and so eddy viscosity coefficient at the bottom is defined in the case of existing of bed sediment stream.

\section{Mathematical description of flow with non movable bed}

In the previous paper the analysis of flow in the river in the case of non movable bed and the way of calculation of eddy viscosity coefficient of water at the bottom is given Meyer (1986, 2009a, 2009b, 2009c, 2009d). The condition of flow are given in Figure 1. 


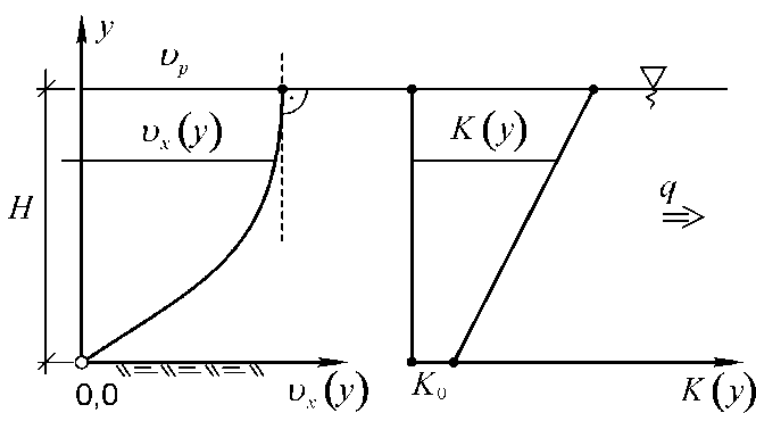

Figure 1. Scheme of flow conditions

$$
v_{x}(y)=\frac{u_{*}}{k}\left[\frac{(U+1) \cdot \ln \left(1+U \cdot \frac{y}{H}\right)-U \cdot \frac{y}{H}}{U}-\right]
$$

and next

$$
v_{0}=\frac{1}{H} \int_{0}^{H} v_{X}(y) d y=\frac{u_{*}}{k} \cdot \ln \left(\frac{U}{e^{3 / 2}}\right)
$$

and furthermore

$$
\begin{gathered}
v_{p}=v_{x}(H)=\frac{u_{*}}{k} \cdot \ln \left(\frac{U}{e}\right) \quad \text { where } \\
u_{*}=\sqrt{g H I}
\end{gathered}
$$

In the above equations, following symbols were used: $e$ - the base of Naperian logarithm; $g$ - acceleration due to gravity; $H$ - the river depth; $I$ - free water surface slope (the bottom slope); $k$ - von Karmann constant; $u_{*}-$ shear velocity; $U$ - parameter of the model; $v_{x}(y)$ - velocity of water at the level; $y, v_{p}$ - surface water velocity; $x, y$ - the basic system of coordinates $(y$ - vertically upward and $x$ - horizontally). The parameter $U$ appearing in the above equations is defined, by Meyer (2009c)

$$
\begin{gathered}
U=\frac{H}{z_{0}} \quad \text { where } \\
z_{0}=\frac{K_{0}}{k \cdot u_{*}}
\end{gathered}
$$

In the equations (5) and (6), $Z_{0}$ - denotes the linear measure of bed roughness, Schlichting (1979) and $K_{0}-$ denotes the eddy viscosity coefficient of water at the bottom. The analysis of hydrodynamics equilibrium based on least energy losses Meyer (2009c) leads to the following relationships:

$$
\begin{gathered}
k=\frac{\ln \left(\frac{U}{e^{3 / 2}}\right)}{\left(\frac{C}{\sqrt{g}}\right)} \\
K_{0}=q \frac{\ln \left(\frac{U}{e^{3 / 2}}\right)}{\left(\frac{C}{\sqrt{g}}\right)^{2} \cdot U}
\end{gathered}
$$




$$
\begin{gathered}
W_{b}=\frac{C_{0} \cdot Q}{U \cdot \ln \left(\frac{U}{e^{3 / 2}}\right)} \cdot\left(\frac{C}{\sqrt{g}}\right)^{2} \text { and } \\
n=\exp \left[-\frac{1}{3} \frac{\ln ^{2} U}{\ln \left(\frac{U}{e^{3 / 2}}\right)}\right]
\end{gathered}
$$

In the above equations, following symbols were used: $C_{0}-$ is the sediment particles concentration in water at the bottom $[g / 1]$; $C$ - velocity constant in Chezy equation; $n$ - roughness coefficient of the river bed by Maning ; $Q$ - flow in river $\left[m^{3} / s\right] ; q$ - flow in river per unit width $\left[\mathrm{m}^{2} / \mathrm{s}\right] ; w_{b}$ - bottom sediment stream $[\mathrm{g} / \mathrm{s}]$.

The relationship (10) represents relation between roughness coefficient of the bottom by Maning and the parameter $U$ in the case of non movable bed and in the case when the river banks do not influence the tachoida (vertical distribution of water velocity) at the river meridian. Practical calculations indicate that the riverbanks have significant influence on velocity distribution, Meyer (2010). This can be included in the following way. The general relation (10) can also be written as:

$$
n=U^{-\frac{1}{3} \frac{\ln U}{\ln \left(\frac{U}{e^{3 / 2}}\right)}}
$$

Taking equations (2) and (3) it can be proved that:

$$
\frac{1}{3} \frac{\ln U}{\ln \left(\frac{U}{e^{3 / 2}}\right)}=\frac{1}{3}+\frac{v_{p}-v_{0}}{v_{0}}
$$

For further calculations it is convenient to introduce parameter $\delta$ representing riverbanks influence on tachoida at the river meridian:

$$
\frac{\delta}{3}=\frac{1}{3}+\frac{v_{p}-v_{0}}{v_{0}}
$$

Including all the above substitutions the basic relation (10) can now be expressed as:

$$
U=\left(\frac{1}{n}\right)^{\frac{3}{\delta}}
$$

If in the equation 13, the values: $v_{p}$ and $v_{0}$ are taken from equation 2 and 3 we have the case when riverbanks do not influence the tachoida and this case represents value $\delta_{0}$. So we have:

$$
\delta_{0}=1+\frac{3}{2} \frac{1}{\ln \left(\frac{U}{e^{3 / 2}}\right)}
$$

Approximated formula can be used if

$$
1000<U<3500
$$

we have than

$$
\delta_{0}=1.578 \mathrm{U}^{-0.0311}
$$

If there is the riverbanks influence on tachoida, there must be:

$$
\delta>\delta_{0}
$$


In the Table 1, there are given values of parameters: $U, \delta_{0}$, and $\frac{v_{p}-v_{0}}{v_{0}}$ for the case when there is no influence of riverbanks.

Table 1. The values of parameter $\delta_{0}$

\begin{tabular}{cccccccccc}
\hline $\mathrm{n}$ & 0.028 & 0.030 & 0.032 & 0.034 & 0.036 & 0.038 & 0.040 & 0.042 & 0.044 \\
$\mathrm{U}$ & 7500 & 6500 & 5000 & 4080 & 3400 & 2870 & 2440 & 2088 & 1800 \\
$\frac{v_{p}-v_{0}}{v_{0}}$ & 0.0674 & 0.0694 & 0.0714 & 0.0734 & 0.0754 & 0.0774 & 0.0794 & 0.0814 & 0.0834 \\
$\delta_{0}$ & 1.202 & 1.208 & 1.204 & 1.220 & 1.226 & 1.232 & 1.238 & 1.244 & 1.250 \\
\hline
\end{tabular}

The relationship (14) allows to calculate further parameters of the flow model i.e.: von Karman constant and eddy viscosity coefficient of water at the bottom $K_{0}$. It can be done when we know $\delta$ and it requires field experiments. But it is also essential to indicate how the value $\delta$ depends on flow in the river. For further analysis it is convenient to introduce function $F(n)$ :

$$
\begin{gathered}
F(n)=\frac{\ln \left(\frac{U}{e^{3 / 2}}\right)}{U} \text { and so } \\
K_{0}=q \cdot \frac{F(n)}{\left(\frac{C}{\sqrt{g}}\right)^{2}}
\end{gathered}
$$

Exact calculation gives the following relation:

$$
F(n)=\frac{3}{\delta} \cdot n^{\frac{3}{\delta}} \cdot\left[\ln \left(\frac{1}{n}\right)-\frac{\delta}{2}\right]
$$

The next step is to express the function (19) as multiplication of power functions:

$$
F(n)=C_{*} \cdot n^{b} \cdot \delta^{a}
$$

The range of practical values of variables is:

$$
0.02 \leq n \leq 0.05 \quad \text { and } \quad 1.2 \leq \delta \leq 1.4
$$

The approximation of the function (20) can be done using least square method. It gives

$$
C_{*}=0.228 ; \quad a=\frac{13}{2} ; \quad b=1.95
$$

If the range of changes of the values: $n$ and $\delta$ is limited to the case of lower Odra river it comes:

$$
0.027 \leq n \leq 0.035 \quad \text { and } \quad 1.2 \leq \delta \leq 1.4
$$

and the approximation gives:

$$
C_{*}=0.181 ; \quad a=\frac{20}{3} ; \quad b=\frac{9}{5}
$$

The aim of expressing the function (17) in terms of relationship (20) is to allow estimation of the parameter $\delta$ more precisely. Statistical analysis of flow parameters based on field experiments suggest that there is high dependence of the following relations: 


$$
\begin{gathered}
U=A_{1} \cdot\left(\frac{C}{\sqrt{g}}\right)^{B_{1}} \text { and } \\
F(n)=A_{2}\left(\frac{C}{\sqrt{g}}\right)^{B_{2}}
\end{gathered}
$$

In the above equations the symbol $C$ denotes the velocity constant for the Chezy equation. The relationships (20) and (21) suggests that now for describing flow in the river as independent variables we take:

$$
T=\sqrt{g} \cdot\left(\frac{\sqrt{I}}{q}\right)^{0.1} \text { and } \frac{C}{\sqrt{g}}
$$

Using these new variables we can present Maning roughness coefficient and the depth as:

$$
n=\left(T \cdot \frac{C}{\sqrt{g}}\right)^{-\frac{10}{9}} \text { and } H=\left[\frac{C}{\left(T \cdot \frac{C}{\sqrt{g}}\right)^{\frac{10}{9}}}\right]^{6}
$$

Comparing equations (14) and (21) and equalizing the exponents appearing on the both side of the expressions it gives:

$$
B_{1}=\frac{10}{3 \delta} \quad \text { and } \quad A_{1}=T^{B_{1}}
$$

and so we have also

$$
U=\left(T \cdot \frac{C}{\sqrt{g}}\right)^{\frac{10}{3 \delta}}
$$

In similar way we can compare equations (20) and (22) obtaining:

$$
B_{2}=\frac{10 b}{9} \quad \text { and } \quad \delta=\text { const } \cdot T^{\frac{10 b}{9 a}}
$$

Finally it is possible to write down following relations:

$$
\begin{gathered}
F(n)=C_{*} \cdot \lambda^{a} \cdot\left(\frac{\sqrt{g}}{C}\right)^{\frac{10 b}{9}} \text { where } \\
\lambda=\left(\frac{A_{2}}{C_{*}}\right)^{\frac{1}{a}} \quad \text { and therefore } \\
\delta=\lambda \cdot T^{\frac{10 b}{9 a}}
\end{gathered}
$$

If for the values: $C_{*}, a$ and $b$ we take those from the range $0.0275 \leq n \leq 0.035$ it gives 


$$
\begin{aligned}
& U=\left(T \cdot \frac{C}{\sqrt{g}}\right)^{\frac{10}{3 \delta}} \\
& F(n)=0.181 \cdot \lambda^{\frac{20}{3}} \cdot\left(\frac{\sqrt{g}}{C}\right)^{2} \\
& \delta=\lambda \cdot \mathrm{T}^{0.3}
\end{aligned}
$$

In the set of the relationships (31) all the values were related to the conditions of Lower Odra river. However the approximation using equation (20) can be done for different rivers. Essential conclusion is that the parameter $\lambda$ which is of local character is constant and does not vary with depth. This parameter can be calculated based on field measurements of tachoida at chosen river cross section. For each flow we have then $U$ which can be evaluated using the method given by the author in the previous paper Meyer (2009c), Stone at all (2007).

Knowing the values of: depth, slope, and $U$ and flow $q$ we can apply for further calculation following relation

$$
\lambda \cdot \ln U=0.3 \cdot T^{-0.3} \cdot \ln \left(T \cdot \frac{C}{\sqrt{g}}\right)
$$

In the above equation the only unknown value is $\lambda$ and it can be approximated using least square method from the set $\left\{v_{i}, T_{i}, C_{i}\right\}$. The evaluation proceeded for Lower Odra river using data by Buchholz (1989) gives $\lambda=1.165$.

\section{The Concept of Including Bed Sediment in River Flow}

The description of flow in the river can be based upon energy budget. If we compare energy changes in two different river cross section there are energy losses between them. In steady uniform flow the energy losses are usually, given in term of roughness coefficient by Maning Prandtl (1956). We have then:

$$
\frac{d}{d x}\left(h_{\text {loss }}\right)=\frac{q^{2}}{H^{\frac{10}{3}}} \cdot n^{2} \quad \text { where }
$$

$h_{\text {loss }}-$ is the head lost between two cross sections.

The equation 33 was derived for the case of non movable bed. If we introduce bed sediment stream we create in fact a mixture of water and solid particles close to the bottom. That mixture has higher eddy viscosity coefficient by comparison to the kinematic viscosity of water. The viscosity of the mixture was investigated by Nowh (1989).

The viscosity of the mixture according to Nowh research is based upon concentration $C_{0}[g / l]$ of the sediment, close to the bottom. It needs to estimate first the bed sediment stream $w_{b}$, von Rijn (1982), Zanke (2003), Graf(1984), Yalin (1972). That can also be taken from the previous paper Meyer (2009b, 2009c):

$$
W_{b}=\left(\frac{C}{\sqrt{g}}\right)^{2} \cdot \frac{C_{0} \cdot Q}{U \cdot \ln \left(\frac{U}{e^{3 / 2}}\right)}
$$

In fact the bed sediment stream can be calculated using different equations of several authors. Comparison of different formula for the conditions of Lower Odra River was don by Meyer and Pluta (2001). From these research it comes that Acker-White (1973) formulae gives satisfactory results. This method was verified in many field tests Meyer (2009a) for Lower Odra river, and it was finally taken for further research. The relation between concentration $C_{0}$ of the sediment-water mixture close to the bottom was given by Nowh (1989). It has the following form: 


$$
\frac{K_{o b}}{v}=\frac{1+1.25 \cdot C_{0}+6,25 \cdot C_{0}^{2}+15.62 \cdot C_{0}^{3}}{1+(s-1) \cdot C_{0}}
$$

For the rough estimation approximate formula can be used:

$$
\frac{K_{o b}}{v}=10.418 \cdot C_{0}^{1.885}
$$

In the above equations $K_{o b}$ - denotes eddy viscosity coefficient of the sediment-water mixture close to the bottom, and $s-$ is the ratio of sediment density to the water . Usually it is assumed $s=2.65$. The symbol $v-$ denotes kinematic viscosity of water. The ratio $K_{o b} / v$ for different concentration $C_{0}$ is given in table 2 .

Table 2. The values $K_{o b} / v=f\left(C_{0}\right)$

\begin{tabular}{cccccc}
\hline$C_{0}[g / l]$ & 0.5 & 1.0 & 1.5 & 2.0 & 2.5 \\
$K_{o b} / v$ & 2.82 & 9.10 & 20.04 & 36.27 & 58.62 \\
\hline
\end{tabular}

In this way for the flowing stream of water in the river we have now two different values of eddy viscosity coefficient close to the bottom:

1) $K_{o}$ - eddy viscosity coefficient which is created at the bottom to reach equilibrium state which is given by least energy losses and controlled by bed roughness and,

2) $K_{o b}$ - eddy viscosity coefficient which is created at the bottom by mixture sediment- water.

The energy losses of the water stream along a certain distance, they result from both viscosities. The nature of energy losses caused by bed roughness is defined by equation 33 . The nature of energy losses caused by $K_{o b}-$ is still a matter of research. To indicate the role of $K_{o b}$ - viscosity in producing resulting energy losses it has been assumed that both viscosities share the some equation 33, because they are coming from turbulence. Equation (33) can be described in term of $K_{o}$. We have then according to the equations 18 and 19;

$$
n=\left[\frac{K_{0}}{g \cdot I^{1 / 10} \cdot q^{4 / 5} \cdot C_{*} \cdot \delta^{a}}\right]^{\frac{5}{9+5 a}}
$$

So if we want to present the resulting energy losses created by both eddy viscosity coefficients, it should read:

$$
\begin{aligned}
& \frac{d}{d x}\left(h_{\text {loss }}\right)=\text { const }\left[\left(K_{0}-K_{0 b}\right)^{\frac{10}{9+5 a}}+K_{0 b}^{\frac{10}{9+5 a}}\right] \text { where } \\
& \text { const }=\frac{q^{2}}{H^{10 / 3}}\left[\frac{1}{g \cdot I^{1 / 10} \cdot q^{4 / 5} \cdot C_{*} \cdot \delta^{a}}\right]^{\frac{10}{9+5 a}}
\end{aligned}
$$

From equation 37 it comes that now we have to introduce two different roughness coefficient by Maning:

- $\quad$ one static roughness coefficient by Maning $n_{s t}$ related to the case of non movable bed, and

- the other dynamic roughness coefficient by Maning $n_{d}$ related to the case of movable bed.

They are defined according to the formula equation 36 :

$$
\begin{gathered}
n_{s t}=\left[\frac{K_{0}}{g \cdot I^{1 / 10} \cdot q^{4 / 5} \cdot C_{*} \cdot \delta^{a}}\right]^{\frac{5}{9+5 a}} \text { and } \\
n_{d}=\left[\frac{K_{0}-K_{0 b}}{g \cdot I^{1 / 10} \cdot q^{4 / 5} \cdot C_{*} \cdot \delta^{a}}\right]^{\frac{5}{9+5 a}}
\end{gathered}
$$


It means that the flowing stream in the case of non movable bed "feels" $n_{s t}$ coefficient and in the case of movable bed "feels" $n_{d}$ coefficient. It can also be seen that

$$
n_{S}>n_{d}
$$

The analysis of Equation 37 suggests that the energy losses reaches minimum values when:

$$
\frac{d}{d x}\left(h_{\text {loss }}\right)=\min , \text { when } \quad K_{o b}=\frac{1}{2} K_{0}
$$

That is a theoretical value because in the practice the amount of carried is limited. So we can say that the flowing steam tends to minimize the energy losses at the bottom by sucking sediment particles and creating sediment concentration which produces eddy viscosity coefficient $K_{o b}$ and diminishing the energy losses according to the equation 37, if the amount of bed sediment allows the phenomenon to develop to satisfy equation 42 . The presented above concept of explaining the influence of bed sediment stream on water flow in the river is based upon assumption that the nature of creating energy losses by both eddy viscosity coefficients is the some. It needs further research to estimate more precisely how they shear producing energy losses. For the conditions of Lower Odra river the equations 49 and 40 takes form:

$$
\begin{gathered}
n_{s t}=\left[\frac{K_{0}}{g \cdot I^{1 / 10} \cdot q^{4 / 5} \cdot 0.181 \cdot \delta^{a}}\right]^{\frac{5}{18}} \\
n_{d}=\left[\frac{K_{0}-K_{0 b}}{g \cdot I^{1 / 10} \cdot q^{4 / 5} \cdot 0.181 \cdot \delta^{20 / 3}}\right]^{\frac{5}{18}} \text { and } \\
\frac{n_{s t}}{n_{d}}=\left[\frac{K_{0}}{K_{0}-K_{0 b}}\right]^{\frac{8}{15}}
\end{gathered}
$$

\section{Evaluative Example}

As an example of practical application of the presented above method the flow in Lower Odra river was taken. As the first step it needs to assume the composition of sediment at the bottom and to calculate static roughness coefficient. For the evaluative example it has been adopted formulae presented in the previous paper Meyer (2009c)

$$
\begin{gathered}
n_{s t}=0.386 \cdot \frac{D_{z}^{1 / 6}}{\sqrt{g}} \text { where } \\
D_{z}^{1 / 6}=\Sigma\left(p_{i} \cdot D_{i}^{1 / 6}\right) \text { and so } \\
C=2.63 \cdot \sqrt{g} \cdot\left\{\sum\left[\mathrm{p}_{\mathrm{i}}\left(\frac{D_{i}}{H}\right)^{1 / 6}\right]\right\}^{-1}
\end{gathered}
$$

In the above equations $\left\{p_{i}, D_{i}\right\}$ denotes the set of values from the sieve curve of the sediments; $D_{z}-$ denotes the representative diameter $[\mathrm{m}]$ with reference to the roughness coefficient. The calculations were proceeded for two boundary cases of the sediment composition

$$
\begin{aligned}
& \text { - case 1: } \quad D_{1}=0.0001 \mathrm{~m} ; \quad p_{1}=0.8 \\
& D_{2}=0.001 \mathrm{~m} ; \quad p_{2}=0.2 \text { and } \\
& \text { - case 2: } \quad D_{1}=0.0001 \mathrm{~m} ; \quad p_{1}=0.2 \\
& D_{2}=0.001 \mathrm{~m} ; \quad p_{2}=0.8
\end{aligned}
$$

The results are given in Table 3. 
Table 3. The parameters: $n_{s t}, C, D z[m m]$

\begin{tabular}{llll}
\hline Case & $n_{s t}$ & $\boldsymbol{C}$ & $D_{Z}[\mathrm{~mm}]$ \\
\hline 1 & 0.0290 & 43.44 & 0.17 \\
2 & 0.0358 & 35.19 & 0.67 \\
\hline
\end{tabular}

For the further calculations it has been assumed according to the field measurements: depth $H=4.5 \mathrm{~m}$ and slope $I=10^{-5}$. For each static roughness coefficient by Maning following parameters were calculated:

$$
C=\frac{1}{n_{s t}} \cdot H^{1 / 6} ; \quad q=\frac{1}{n_{s t}} \cdot H^{5 / 3} \sqrt{I} \quad \text { and } \quad T=\sqrt{g} \cdot\left(\frac{\sqrt{\mathrm{I}}}{\mathrm{q}}\right)^{01}
$$

The next step was to estimate $\delta=1.165 \cdot T^{0.3}$ and the functions $U$ and $F(n)$ according to the equation 31 . Finally eddy viscosity coefficient of water at the bottom $K_{0}$ from Equation 18, and von Karman constant from equation 7 was evaluated. The results are given in Table 4.

Table 4. Flow parameters for Lower Odra

\begin{tabular}{cccccccc}
\hline$n_{s t}$ & 0.035 & 0.034 & 0.033 & 0.032 & 0.031 & 0.030 & 0.029 \\
$C$ & 36.71 & 37.79 & 38.93 & 40.15 & 41.44 & 42.83 & 44.30 \\
$q\left\lfloor\mathrm{~m}^{2} / \mathrm{s}\right\rfloor$ & 1.11 & 1.14 & 1.17 & 1.21 & 1.25 & 1.29 & 1.34 \\
$T$ & 1.743 & 1.738 & 1.733 & 1.728 & 1.722 & 1.716 & 1.711 \\
$\delta$ & 1.376 & 1.375 & 1.374 & 1.373 & 1.371 & 1.370 & 1.368 \\
$U$ & 1490 & 1597 & 1717 & 1848 & 1996 & 2161 & 2346 \\
$K_{0}\lfloor\mathrm{~m} 2 / s\rfloor$ & $2.95 \cdot 10^{-5}$ & $2.69 \cdot 10^{-5}$ & $2.45 \cdot 10^{-5}$ & $2.24 \cdot 10^{-5}$ & $2.04 \cdot 10^{-5}$ & $1.84 \cdot 10^{-5}$ & $1.67 \cdot 10^{-5}$ \\
$F(n)$ & $3.65 \cdot 10^{-3}$ & $3.43 \cdot 10^{-3}$ & $3.23 \cdot 10^{-3}$ & $3.04 \cdot 10^{-3}$ & $2.86 \cdot 10^{-3}$ & $2.67 \cdot 10^{-3}$ & $2.50 \cdot 10^{-3}$ \\
$k$ & 0.495 & 0.487 & 0.478 & 0.470 & 0.461 & 0.450 & 0.442 \\
\hline
\end{tabular}

From the Table 4, it comes that the eddy viscosity coefficient which satisfies hydrodynamic equilibrium follows the bellow formula $15 v<K_{0}<30 v$. The following step is to estimate how bed sediment stream influence the roughness coefficient by Maning $n_{d}$. For different chosen values at $K_{0 b}$ the results are given in Table 5 .

Table 5. The values of $n_{d}$ for the Lower Odra Rriver

\begin{tabular}{cccccccc}
\hline \multirow{2}{*}{$n_{\text {st }}$} & \multicolumn{7}{c}{$K_{\text {ob }} / v$} \\
\cline { 2 - 8 } & 1.0 & 2.0 & 3.0 & 4.0 & 5.0 & 6.0 & 7.0 \\
\hline 0.035 & 0.0346 & 0.0342 & 0.0338 & 0.0334 & 0.0330 & 0.0325 & 0.0321 \\
0.034 & 0.0336 & 0.0332 & 0.0327 & 0.0323 & 0.0318 & 0.0313 & 0.0308 \\
0.033 & 0.0326 & 0.0321 & 0.0317 & 0.0312 & 0.0307 & 0.0301 & 0.0296 \\
0.032 & 0.0315 & 0.0311 & 0.0306 & 0.0300 & 0.0295 & 0.0289 & 0.0283 \\
0.031 & 0.0305 & 0.0300 & 0.0295 & 0.0289 & 0.0283 & 0.0277 & 0.0270
\end{tabular}

During field measurements for Lower Odra river it comes that the obtained roughness coefficient by Maning equals to 0.029 . For static value $n_{s}=0.033$ it means that $K_{0 b}=8 \cdot v$. According to the calculated values $n_{d}$ in Table 5, it was possible to calculate the bed sediment stream $w_{b}=[\mathrm{kg} / \mathrm{s}]$. Assuming $Q=200 \mathrm{~m} / \mathrm{s}$ the results are given in Table 6. 
Table 6. The values of $w_{b}=[\mathrm{kg} / \mathrm{s}]$, bed sediment stream

\begin{tabular}{cccccccc}
\hline \multirow{2}{*}{$n_{\text {st }}$} & \multicolumn{7}{c}{$K_{\text {ob }} / v$} \\
\cline { 2 - 8 } & 1.0 & 2.0 & 3.0 & 4.0 & 5.0 & 6.0 & 7.0 \\
\hline 0.035 & 6.47 & 9.54 & 11.97 & 14.07 & 15.94 & 17.65 & 19.25 \\
0.034 & 5.97 & 8.80 & 11.04 & 12.97 & 14.70 & 16.28 & 17.74 \\
0.033 & 5.48 & 8.80 & 10.14 & 11.92 & 13.50 & 14.96 & 16.30 \\
0.032 & 5.03 & 7.42 & 9.31 & 10.94 & 12.39 & 13.73 & 14.96 \\
0.031 & 4.60 & 6.68 & 8.51 & 10.0 & 11.33 & 12.55 & 13.68 \\
\hline
\end{tabular}

The field measurements indicates that the bed sediment stream varies within the range $w_{b}=10 \mathrm{~kg} / \mathrm{s} \div 16 \mathrm{~kg} / \mathrm{s}$. Finally the changes of the depth, according to the changes of roughness coefficient $n_{d}$ were calculated. The results are given in Table 7 .

Table 7. The values of depth fall $H[m]$ due to bed sediment stream

\begin{tabular}{cccccccc}
\hline \multirow{2}{*}{$n_{\text {st }}$} & \multicolumn{6}{c}{$K_{o b} / v$} \\
\cline { 2 - 8 } & 1.0 & 2.0 & 3.0 & 4.0 & 5.0 & 6.0 & 7.0 \\
\hline 0.035 & 4.47 & 4.44 & 4.41 & 4.38 & 4.34 & 4.30 & 4.27 \\
0.034 & 4.47 & 4.44 & 4.40 & 4.36 & 4.32 & 4.28 & 4.24 \\
0.033 & 4.47 & 4.43 & 4.39 & 4.35 & 4.31 & 4.26 & 4.22 \\
0.032 & 4.46 & 4.42 & 4.38 & 4.33 & 4.29 & 4.23 & 4.18 \\
0.031 & 4.46 & 4.41 & 4.37 & 4.31 & 4.26 & 4.21 & 4.14 \\
\hline
\end{tabular}

From the Table 7 it comes that for the measuremed values of roughness coefficient by Maning the depth fall can reach even $25 \mathrm{~cm}$ having the initial value $4.5 \mathrm{~m}$.

\section{Conclusions}

5.1 The paper presents the model of water flow in a river in the case when bed sediment transport influences the flow parameters. The model is based upon earlier research carried on by the author Meyer (1986, 2009). The concept of including bed sediment influence on the flow parameters utilizes the conclusion that the water stream in order to keep the least energy losses principle, creates at the bottom certain eddy viscosity coefficient of water. The existing of bed sediment stream results in production of eddy viscosity coefficient of the mixture of sediment - water at the bottom. It makes the effective Maning roughness coefficient smaller. As the results of it, the water depth diminish.

5.2 To include the bed sediment influence on river flow it is suggested to introduce two different roughness coefficients by Maning. One referred to the flow with non-movable bed so called static and the second for the case with movable bed so called dynamic. The dynamic coefficient is smaller than the static one. If the roughness coefficient by Maning is calculated based upon field measurements it is referred as dynamic coefficient including bed sediment transport. Appropriate static coefficient is always bigger.

5.3 Important factor of the model is the influence of river banks on the vertical distribution of water velocity (tachoida) at the midstream. The influence of the river banks results in increasing velocity of flowing water at the upper layer. The model proposed the way of calculation, in order to include it in flow parameters.

5.4 An example of practical calculations using the presented model is given. The initial data were taken for the case of Lower Odra river. The results of the calculations confirms the data obtained from field measurement.

5.5 The program of further research includes the analysis of the principles of energy losses in flowing stream due to the bed sediment transport. In the present paper in order to simplify the model it has been assumed that both energy losses components are given by the some sort of equation. That needs further investigation. 


\section{References}

Ackers, P., \& White, R.W. (1973). Sediment transport new approach and analysis. J.Hydraul. Div., 99(NY-11), 2041-2060.

Buchholz, W. (1989). Wind influence on flows at river mouth. Proceedings of the Maritime Institute of Gdańsk.

Graff, W. H. (1984). Hydraulics of Sediment Transport. Water Research Publication, Hittleton, Colorado.

Meyer, Z. (1986). Vertical circulation in density stratified reservoir. Encyclopaedia of Fluid Mechanics, 2, 572-636. Gulf Publishing Co. Huston.

Meyer, Z. (2009a). Hydraulics conditions of water flow in river mouth. Studia Geotechnica at Mechanica, $X X X I(3), 3-25$.

Meyer, Z. (2009b). Sediment transport calculation using the Ackers-White method in river with compound cross-section. River, Coastal and Estuarine Morphodynamics, Santa Fe-Argentyna, A. Balkena Book (pp. 299-302).

Meyer, Z. (2009c). Modified Logarythmic Tachoida Applied to Sediment Transport in River. Acta Geophysica Institute of Geophysics. Polish Academy of Science, 57(3), 743-759.

Meyer, Z. (2009d). An Analysis of the Mechanism of Flow in Ice-Covered Rivers. Acta Geophysica Institute of Geophysics. Polish Academy of Science, 58(2), 337-355.

Meyer, Z. (2010). Estimation of River Banks Influence on Tachoida Shape at Meridian. XXX International School of Hydraulics Polish Academy of Sciences of Wiejce.

Meyer, Z., \& Pluta, M. (2001). Stratified flow model applied to sediment transport in river cavern. Conference Applying of Mechanics in Structure - and Hydroengineering, organized in occasion of 70th birthday of prof. P. Wilde, Institute of Hydroengineering Polish Academy of Science, Gdańsk .

Nowh, M. ( 1989). The von Kàrmàn coefficient in sediment laden flow. Journal of the Hydraulics Research, 27(4), 477-499.

Olsen, M. R. B., \& Oldervik, O. (1995). Three-dimensional Numerical Modelling of Water Flow in a River with Large Bed Roughness, IAHR. Journal of Hydraulics Research, 33(4).

Prandtl, L. (1956). Dynamics of flows. PWN Warszawa.

Schlichting, H. (1979). Boundary Layer Theory, Mc Graw-Midl.

Stone, M. C., \& Hotchkiss, R. H. (2007). Evaluating velocity measurement techniques in shallow streams. Journal of the Hydraulics Research, 45(6), 752-762.

Van Rijn, L. C. (1982). Equivalent Roughness of Alluvial Bed. ASCE Journal of Hydraulics Engineering, 108(10).

Yalin, M. S. (1972). Mechanics of Sediment Transport. Braunschweig: Pergamon Press.

Zanke, U. C. E. (2003). On the Influence of Turbulence on the Initiation of Sediment Motion. Int. J. of Sediment Research, 18(1), 17-31.

\section{Copyrights}

Copyright for this article is retained by the author(s), with first publication rights granted to the journal.

This is an open-access article distributed under the terms and conditions of the Creative Commons Attribution license (http://creativecommons.org/licenses/by/3.0/). 